\title{
On the possibility of welfare-enhancing hard core cartels
}

\author{
Iwan Bos • Erik Pot
}

Received: 8 July 2011 / Accepted: 22 December 2011 / Published online: 3 January 2012

(C) The Author(s) 2011. This article is published with open access at Springerlink.com

\begin{abstract}
The conventional wisdom is that cartels which merely lead to lower production levels and higher prices are detrimental to social welfare. This paper explores the extent to which this is generally valid. We derive necessary and sufficient conditions for the existence of a hard core cartel that is beneficial for firms and society at large. Considering both strong (with side payments) and weak (without side payments) hard core cartel contracts, we find that (i) both strong and weak welfare-enhancing cartels exist when at least one firm makes a loss on part of its sales in competition, (ii) a welfare-enhancing strong cartel exists whenever there is a difference in unit cost at competitive production levels, and (iii) a welfare-enhancing weak cartel exists when the profit margin on all sales is positive and the cost difference is sufficiently large.
\end{abstract}

Keywords Antitrust · Cartels · Welfare-enhancing collusion

JEL Classification $\quad \mathrm{L} 1 \cdot \mathrm{L} 4$

\section{Introduction}

Standard economic theory teaches that cartels are detrimental to social welfare. Firms engaging in a cartel generally limit production and raise prices, which results in

An earlier version of this work was titled 'Welfare-Enhancing Hard Core Cartels'.

I. Bos $(\bowtie)$

Department of Organization and Strategy, Maastricht University School of Business and Economics, P. O. Box 616, 6200 MD Maastricht, The Netherlands

e-mail: i.bos@maastrichtuniversity.nl

E. Pot

Department of Quantitative Economics,

Maastricht University School of Business and Economics, Maastricht, The Netherlands 
allocative inefficiencies and additionally leads to a redistribution of income from consumers to producers. Compared to a competitive market, some customers refrain from purchasing (or buy less-preferred substitutes), while others have to spend a larger portion of their budget to obtain the product or service. In addition, cartels are believed to give rise to technical and $\mathrm{X}$-inefficiencies. In absence of competition, firms are thought to lack incentives to organize their operations and production as efficient as possible. ${ }^{1}$ As the conventional wisdom is that cartels have no obvious benefits for society, most capitalist societies have adopted antitrust laws declaring cartel contracts illegal. In particular, the antitrust system typically does not allow for an assessment of the costs and benefits of a cartel arrangement to determine its (il)legality and proving its existence often suffices to establish an infringement of the antitrust laws.

Despite this apparent consensus, however, there is a steadily growing literature (to be reviewed below) pointing out potential welfare-enhancing effects of cartels. Moreover, arguments pertaining to the positive welfare impact of cartel agreements can still be found in antitrust practice. For instance, the Netherlands Competition authority recently fined several Dutch, German and Danish firms operating in the shrimp fishery sector for fixing minimum prices and establishing quota at the end of the 1990s. ${ }^{2}$ Part of the cartel member's defense was that the agreement has been beneficial for all parties involved as it ensured maintenance of the industry, while safeguarding the environment. Yet, both the informal and formal arguments highlighting the welfareenhancing potential of cartels typically apply to rather specific cases only. This raises the question to what extent we may expect cartel contracts to lead to higher welfare standards.

The purpose of this paper is to shed some light on this issue by deriving necessary and sufficient conditions for the existence of a welfare-enhancing cartel. Our approach to welfare is 'neutral' in the sense that we define it as the sum of consumer and producer surplus. Moreover, we restrict ourselves to horizontal cartels that have a direct impact on market prices. ${ }^{3}$ In practice, such so-called hard core cartels can take a variety of forms. ${ }^{4}$ The Organization for Economic Co-operation and Development (OECD) defines a hard core cartel as " an anticompetitive agreement, anticompetitive concerted practice, or anticompetitive arrangement by competitors to fix prices, make rigged bids (collusive tenders), establish output restrictions or quotas, or share or divide markets by allocating customers, suppliers, territories, or lines of commerce." 5

\footnotetext{
${ }^{1}$ See, for instance, OECD (2000), Spagnolo (2006) and Hüschelrath and Weigand (2010). In general, inefficiencies attributed to (hard core) cartels are the same as those associated with monopoly organizations. One could further think of inefficiencies that arise because firms may spend part of their resources to establish and maintain the cartel and to protect its market power.

2 See Case 2269/Garnalen, decision by the NMa (the Netherlands Competition authority), 2003. Available at: http://www.nma.nl/images/2269BLD22-151172.pdf.

${ }^{3}$ Some horizontal cartels only affect the price mechanism indirectly. See, for example, Genesove and Mullin (2001) which describes how the sugar cartel in the U.S. (1927-1936) colluded on business practices to facilitate tacit collusion on prices.

${ }^{4}$ Harrington (2006), for example, contains a detailed description of about twenty European cartel cases over 2000-2004. This study illustrates the remarkable variety in hard core cartels regarding both their content and their organization.

5 OECD report (1998).
} 
In our analysis, we focus on hard core cartels with and without side payments that lead exclusively to a decrease of industry output and higher prices and explore under which conditions there exists a cartel agreement that is beneficial for firms and society at large. Our approach differs from the standard theoretical literature on collusion as we do not analyze cartel conduct in the context of a specific oligopoly model. Instead, we consider a simple but fairly general framework in which we derive conditions on a competitive situation that is defined as some point on the demand curve. Put differently, we explore what the market situation should look like in order for there to be a profitable cartel that generates a higher total surplus. In the real world, competition leads to a striking variety of market outcomes that can be rationalized in many ways. Therefore, we do not limit ourselves ex ante by assuming a particular oligopoly setting with corresponding equilibria.

Summarizing our main findings, welfare-enhancing cartels with side payments (strong cartels) and without side payments (weak cartels) both exist when price is below unit costs at competitive production levels for at least one firm, i.e., when at least one firm makes a loss on part of its sales. In this situation, there exists a hard core cartel that leads to an increase of allocative efficiency. Moreover, such a cartel allows for a substantial increase of firm profits as it reduces the amount of unprofitable sales and improves the price-cost margin on remaining sales. A welfare-enhancing strong cartel exists whenever there is a difference in unit costs at competitive production levels. In this case, individual and total profits can increase by shifting production from the less to the more efficient firm. It is shown that there always exists a cartel contract for which this profit increase dominates the loss in consumer surplus.

Finally, and perhaps most striking, we find that a welfare-enhancing weak cartel exists when the profit margin on all sales is positive and the difference in unit cost is sufficiently large. Here, the price increase that results from the cartel is sufficient to compensate the inefficient firm for reducing its outputs. At the same time, this price effect should have a limited impact on consumer welfare in order for aggregate welfare to increase, which requires market demand to be sufficiently inelastic. Therefore, and all else equal, lower market demand elasticity not only makes collusion more attractive, but also increases the likelihood that the cartel is welfare-enhancing.

Reviewing the existing literature, there are at least three arguments indicating how horizontal collusion may promote social welfare. One strand of work argues that a cartel can have a welfare-enhancing effect when it is ancillary to cooperative productive activity engaged in by the cartel members (so-called 'non-naked' cartel agreements). ${ }^{6}$ This is essentially the view of the Chicago school of economics. The key argument is that when business practices such as price-fixing or market division form an essential part of a bigger arrangement between firms, then a cartel could potentially increase productive efficiency more than it reduces allocative efficiency. ${ }^{7}$ For instance, a cartel

\footnotetext{
6 A cartel agreement is 'naked' when such a countervailing effect is absent.

7 This is also the prime rationale for exempting export cartels from antitrust laws. First, the cartel allows for higher selling prices and, second, members can save costs, e.g., because they can use one and the same sales organization. Within a country, therefore, a cartel is likely to increase productive efficiency more than it reduces allocative efficiency, because costs due to a misallocation of resources are expected to be borne mainly by foreign customers. See Dick (1996) for a detailed discussion and analysis of the Webb-Pomerene
} 
between sellers may increase social welfare when participating firms advertise jointly using media that they cannot afford individually, even though this requires an agreement upon the prices that will be advertised. ${ }^{8}$ In fact, deterring or prosecuting efficient cartels could result in higher market prices as unit production costs will be higher in absence of the cartel. ${ }^{9}$

A second strand of literature highlights the possibility that unrestricted competition may not necessarily lead to a competitive equilibrium. Most notably, a competitive equilibrium may be absent in industries with large fixed costs and decreasing long-run average costs. That is, with increasing returns markets may have an empty core. ${ }^{10}$ This basically means that, even when firms are willing to compete, competition is not viable in certain markets. As a result, some sort of strategy coordination between firms is required to maintain an industry, thereby contributing to social welfare. One particular solution for these type of markets is to allow sellers to establish sales quotas. ${ }^{11}$ Such a hard core cartel would be welfare-enhancing as it saves a surplus generating business that would not exist with unrestricted competition. It is noteworthy that the cost conditions under which the core may be empty sometimes seem to describe quite closely the cost structure in manufacturing industries such as cement and steel; industries that repeatedly have witnessed hard core cartel behavior. ${ }^{12}$

A third strand of work shows that naked cartels may result in higher welfare standards even in markets with constant or decreasing returns. Taking a dynamic approach, it can be argued that cartels may (temporarily) lead to an increase (or stabilization) instead of a decrease in industry output. ${ }^{13}$ For example, under the assumption that firms are risk-averse, Dewey (1979) argues that a cartel will attract additional production given that barriers to entry are limited. ${ }^{14}$ In a related vein, Rotemberg (1998) shows that with imperfect financial markets and demand uncertainty cartels may lead to higher output levels than under (perfect) competition. The reason is that the additional profits that result from the cartel either encourages entry or provides cartel members with the incentive to invest in production capacity. This is confirmed by Fershtman and Pakes

\section{Footnote 7 continued}

Export Trade Act of 1918, which made cartel arrangements between U.S. exporters legal. However, it is doubtful if export cartels are beneficial for social welfare of trading nations together.

${ }^{8}$ See Bork (1993, p. 278).

9 Sproul (1993), for example, finds that prices charged by firms indicted for price fixing gradually rose over the years following the indictment. As the author suggests, one potential explanation for this rather surprising result is that firms had established an economically efficient cartel.

10 See Telser (1996).

${ }^{11}$ See, for instance, Sjostrom (1989) in which it is suggested that cartel behavior in ocean shipping is an attempt to solve the problem of an empty core.

12 See, for example, Bittlingmayer (1982) which argues that the empty core theory is likely to have applied to the classic Addyston Pipe antitrust case. U.S. v. Addyston Pipe and Steel Co., 85 Fed. 271 (6th Cir. 1898).

${ }^{13}$ For example, Kinghorn (1996) and Troesken (1989) find empirical support for expansion of output by cartels. See also Bittlingmayer (1995) which shows that the National Industrial Recovery Act (NIRA), which was an essential part of Franklin Roosevelt's New Deal of 1933, had no significant effects on real output. This contrasts, however, with Taylor (2002) which shows that the NIRA led the U.S. manufacturing industry to reduce outputs.

${ }^{14}$ It is noteworthy that this paper triggered quite a few comments, which perhaps also illustrates the controversy of this topic. See the American Economic Review, Vol. 72, No. 1, 1982. 
(2000), which studies collusion in a structural dynamic setting. They find that collusion may yield more and higher quality products, which more than compensates consumers for collusive prices. Finally, in the context of an infinitely repeated game with quantity competition and demand shocks, Montero and Guzmán (2010) shows that, under certain conditions, a profit-maximizing incomplete cartel may find it optimal to extend production beyond competitive levels. It should be noted, however, that cartels leading to an increase in industry output do not necessarily result in higher welfare standards compared to the competitive alternative. This is so because the increase in consumer surplus may be more than offset by a loss in producer surplus. ${ }^{15}$

In contrast to the above references, this work aims to provide a complete characterization for the existence of welfare-enhancing hard core cartels. Moreover, our paper is complementary as we focus on naked hard core cartels that lead to a reduction in total industry supply in markets in which a competitive equilibrium exists. As we are primarily interested in the welfare effects, we will abstract from issues related to the formation and sustainability of cartels. That is to say, throughout the paper, we assume that profitable cartels are viable. ${ }^{16}$

This paper proceeds as follows. In the next section, the model is described and we establish necessary and sufficient conditions for the existence of an individually rational naked hard core cartel contract. In Sect. 3, these conditions are analyzed in detail. In Sect. 4, we summarize and discuss our main findings. All proofs are relegated to the Appendix.

\section{Model and conditions}

Consider an industry with two firms $i=1,2$. Total cost of producing a quantity of output $q_{i}$ is given by the cost function $C_{i}\left(q_{i}\right)$, which we assume to be increasing and convex, i.e., $C_{i}^{\prime}\left(q_{i}\right)>0$ and $C_{i}^{\prime \prime}\left(q_{i}\right) \geq 0$ at all $q_{i}>0$. Aggregate industry production is denoted by $Q=q_{1}+q_{2}$ and the inverse market demand function is $p(Q)$, which is twice continuously differentiable with $p^{\prime}(Q)<0$ and $p^{\prime \prime}(Q) \leq 0$ at all $Q>0$. Total quantity supplied is assumed to equal total demand, i.e., the market clears. Thus, for a given price-quantity combination $\left(p(Q), q_{1}, q_{2}\right)$, firm $i$ 's profit $\pi_{i}$ and the net consumer surplus $C S$ are respectively given by

$$
\pi_{i}=p(Q) q_{i}-C_{i}\left(q_{i}\right), \quad \text { for } i=1,2,
$$

and

$$
C S=\int_{0}^{Q} p(x) d x-p(Q) Q .
$$

\footnotetext{
15 Röller and Steen (2006), for example, studies a hard core cartel arrangement in the Norwegian cement industry. They find that industry output increased during the cartel regime and that domestic customers actually benefited from the cartel. However, it is also shown that total surplus would have been higher in competition. See Matsui (1989) for a theoretical analysis of how a horizontal cartel may benefit consumers, while making firms worse off.

16 We discuss the implications of this assumption in Sect. 4.
} 
Society's welfare $W$ is defined as the sum of firm profits and consumer surplus:

$$
W=\pi_{1}+\pi_{2}+C S=\int_{0}^{Q} p(x) d x-C_{1}\left(q_{1}\right)-C_{2}\left(q_{2}\right) .
$$

Therefore, for any given $\left(p(Q), q_{1}, q_{2}\right)$, total welfare equals gross consumer surplus minus total production cost.

The starting point of our analysis is a competitive situation, which is some point on the inverse demand curve denoted by $\left(p^{*}, q_{1}^{*}, q_{2}^{*}\right)$, where $p^{*} \equiv p^{*}\left(Q^{*}\right)$. The term 'competition' is used broadly as it may capture any (market-clearing) outcome absent collusion. We make the following assumption about this competitive point:

Assumption $1 C_{1}^{\prime}\left(q_{1}^{*}\right) \leq C_{2}^{\prime}\left(q_{2}^{*}\right)$ and $q_{1}^{*}, q_{2}^{*}>0$.

The first part of Assumption 1 states that, at competitive output levels, marginal production costs of firm 1 are weakly lower than the marginal production costs of firm 2, which is without loss of generality. The second part of Assumption 1 requires both firms to be active in competition. It is important to emphasize that individual production levels need not be equal. Moreover, our analysis does not require any assumption on how $\left(p^{*}, q_{1}^{*}, q_{2}^{*}\right)$ emerges. That is to say, it may result from price competition, quantity competition or any other competitive process.

In what follows, let the collusive price-quantity combination be denoted by $\left(p^{c}, q_{1}^{c}\right.$, $\left.q_{2}^{c}\right)$, where $p^{c} \equiv p^{c}\left(Q^{c}\right)$. As our focus is on hard core cartels that cause a reduction of industry output, we assume $Q^{c}<Q^{*}$ (and therefore $p^{c}>p^{*}$ ). As before, we do not make any specific assumptions about the division of total output. In particular, there may be a change in market shares ( i.e., a redistribution of production can be part of the cartel contract). We consider a cartel contract to be welfare-enhancing whenever the agreement results in more aggregate welfare than the competitive alternative. Thus, a cartel agreement $\left(p^{c}, q_{1}^{c}, q_{2}^{c}\right)$ is welfare-enhancing if $W^{c}>W^{*}$, which is equivalent to

$$
C_{1}\left(q_{1}^{*}\right)+C_{2}\left(q_{2}^{*}\right)-C_{1}\left(q_{1}^{c}\right)-C_{2}\left(q_{2}^{c}\right)>\int_{Q^{c}}^{Q^{*}} p(x) d x .
$$

A hard core cartel arrangement will therefore result in an increase of aggregate welfare only when the decrease in total production cost is strictly larger than the loss in gross consumer surplus. Condition (4) captures the welfare trade-off that is often present when firms cooperate. For example, in a classic discussion of mergers, Williamson (1968) emphasizes the issue of whether the increase in productive efficiency more than makes up for the loss in allocative efficiency, which typically results from higher market concentration. Similarly, by achieving a sufficiently large cost reduction, naked hard core cartels might have a positive effect on welfare, although in our model this will not result from economic integration.

Additionally, we require both firms to benefit from the cartel. Therefore, we only consider cartel agreements for which profits of both firms are strictly higher than in 
competition. We distinguish two types of cartel arrangement; one that includes the possibility of making side payments (strong cartel) and another in which such monetary transfers are absent (weak cartel). ${ }^{17}$ The following definition formalizes this participation constraint.

Definition 1 A hard core cartel agreement $\left(p^{c}, q_{1}^{c}, q_{2}^{c}\right)$ is individually rational if

(i) $\pi_{i}^{c}>\pi_{i}^{*}$, for $i=1,2$ (weak cartel), or

(ii) $\sum_{i=1,2} \pi_{i}^{c}>\sum_{i=1,2} \pi_{i}^{*}$ (strong cartel).

Notice that the first part of this definition is stronger than the second as Definition 1(i) implies Definition 1(ii), but not vice versa. However, to ensure individual rationality, we implicitly assume that total cartel profit of a strong cartel will be distributed such that $\pi_{i}^{c}>\pi_{i}^{*}$, for $i=1,2$.

The main issue is now to establish conditions under which a hard core cartel exists that is both welfare-enhancing and individually rational. Due to concavity of the profit and welfare functions, this is the case if and only if there exists a direction of change from the competitive point $\left(p^{*}, Q^{*}\right)$ for which price goes up (and total output decreases), total surplus increases and individual (in case of a weak cartel) or total (in case of a strong cartel) profits increase. ${ }^{18}$ Notice that, independent of whether price or quantity is the strategic variable, we can represent any change from the competitive point as a change in individual output (e.g., if firms increase prices, total demand goes down, which in turn implies a decrease in individual output for at least one firm). Thus, we can define a vector $\mathbf{u}=\left(u_{1}, u_{2}\right)$, which represents the direction of change from the competitive point in terms of $q_{1}$ and $q_{2}$ respectively. As this change should result in a total output reduction, we exclusively focus on vectors for which $u_{1}+u_{2}<0$.

The impact of a change in output on total welfare, as defined in (3), from a point $\left(p^{*}, Q^{*}\right)$ in the direction $\mathbf{u}$, is then given by the directional derivative

$$
u_{1} \cdot\left(p^{*}-C_{1}^{\prime}\left(q_{1}^{*}\right)\right)+u_{2} \cdot\left(p^{*}-C_{2}^{\prime}\left(q_{2}^{*}\right)\right)
$$

Likewise, the impact of a change in individual outputs from the competitive point in the direction $\mathbf{u}$ on individual and total profits is respectively given by

$$
u_{i} \cdot\left(p^{*}+p^{* \prime} q_{i}^{*}-C_{i}^{\prime}\left(q_{i}^{*}\right)\right)+u_{j} \cdot\left(p^{* \prime} q_{i}^{*}\right), \quad \text { for } i=1,2 \text { and } i \neq j
$$

and

$$
u_{1} \cdot\left(p^{*}-C_{1}^{\prime}\left(q_{1}^{*}\right)\right)+u_{2} \cdot\left(p^{*}-C_{2}^{\prime}\left(q_{2}^{*}\right)\right)+\left(u_{1}+u_{2}\right) \cdot p^{* \prime} Q^{*},
$$

where $p^{* \prime} \equiv d p^{*}\left(Q^{*}\right) / d Q^{*}$. As mentioned above, for a welfare-enhancing cartel to exist, there must be a direction of change for which both welfare and profits increase. Thus, (5) must be positive, which is captured by the following condition.

\footnotetext{
17 This is a common distinction in the literature on collusion. See, for example, Pesendorfer (2000).

18 Both functions have a unique maximum as $\frac{\partial^{2} \pi_{i}}{\partial q_{i}^{2}}<0$ and $\frac{\partial^{2} W}{\partial Q^{2}}<0$.
} 
Condition $1 u_{1} \cdot\left(p^{*}-C_{1}^{\prime}\left(q_{1}^{*}\right)\right)+u_{2} \cdot\left(p^{*}-C_{2}^{\prime}\left(q_{2}^{*}\right)\right)>0$.

Similarly, a decrease in output in the direction $\mathbf{u}$ will have a positive effect on individual and total profits when (6) and (7) are positive. Consequently, for the existence of an individually rational cartel agreement it is required that Condition 2(i), in case of a weak cartel, and Condition 2(ii), in case of a strong cartel, hold for some direction $\mathbf{u}$.

\section{Condition 2}

(i) $u_{i} \cdot\left(p^{*}+p^{* \prime} q_{i}^{*}-C_{i}^{\prime}\left(q_{i}^{*}\right)\right)+u_{j} \cdot p^{* \prime} q_{i}^{*}>0$, for $i=1,2$ and $i \neq j$ (weak cartel).

(ii) $u_{1} \cdot\left(p^{*}-C_{1}^{\prime}\left(q_{1}^{*}\right)\right)+u_{2} \cdot\left(p^{*}-C_{2}^{\prime}\left(q_{2}^{*}\right)\right)+\left(u_{1}+u_{2}\right) \cdot p^{* \prime} Q^{*}>0$ (strong cartel).

In sum, if Condition 1 holds, then there exists a cartel agreement for which $W^{c}>$ $W^{*}$ and if Condition 2 holds, then there exists a cartel agreement for which $\pi_{i}^{c}>\pi_{i}^{*}$, for $i=1,2$. Thus, Condition 1 in conjunction with Condition 2 marks situations in which there exists an individually rational welfare-enhancing cartel arrangement. In the next section, we analyze these conditions in more detail.

\section{Analysis and results}

In this section, we derive necessary and sufficient conditions for the existence of a welfare-enhancing hard core cartel. Starting from some competitive situation $\left(p^{*}, q_{1}^{*}\right.$, $\left.q_{2}^{*}\right)$, the key question is whether there exists a direction $\mathbf{u}=\left(u_{1}, u_{2}\right)$ with $u_{1}+u_{2}<0$ such that Conditions 1 and 2 hold simultaneously. If so, then there exists another point on the market demand curve $\left(p^{c}, q_{1}^{c}, q_{2}^{c}\right)$ for which total production is lower and both profits and aggregate welfare are higher than in competition.

\subsection{Weak cartels}

In focusing on hard core cartel contracts without side payments, the question is if and when Condition 1 and Condition 2(i) hold simultaneously. Let $\pi_{i}^{\prime}\left(q_{i}^{*}\right) \equiv$ $d \pi_{i}\left(q_{i}^{*}\right) / d q_{i}^{*}$. The next result provides a necessary condition for the existence of an individually rational welfare-enhancing weak cartel.

Lemma 1 If there exists an individually rational welfare-enhancing weak cartel, then $\pi_{i}^{\prime}\left(q_{i}^{*}\right)<0$ for at least one firm $i$.

Hence, if an individually rational welfare-enhancing weak cartel exists, then at least one firm would be willing to cut back production. Yet, the competitive situation may be such that an uncoordinated reduction of output is not in a firm's best interest.

Using this result, we can specify necessary and sufficient conditions for the existence of an individually rational welfare-enhancing weak cartel.

Theorem 1 There exists an individually rational welfare-enhancing weak cartel if and only if:

$$
p^{*}-C_{2}^{\prime}\left(q_{2}^{*}\right)<\max \left\{0, \frac{p^{* \prime} q_{2}^{*}\left(p^{*}-C_{1}^{\prime}\left(q_{1}^{*}\right)\right)}{p^{* \prime} q_{2}^{*}-\left(p^{*}-C_{1}^{\prime}\left(q_{1}^{*}\right)\right)}\right\} \text {. }
$$


This result shows that there are two situations in which an individually rational welfareenhancing weak cartel exists. First, such a cartel exists when at least one firm makes a loss on (part of) its sales in competition, i.e., $p^{*}-C_{2}^{\prime}\left(q_{2}^{*}\right)<0$. To provide some intuition, suppose that both firms engage in the following cartel contract. Firm 1 keeps its output constant, while Firm 2 is reducing its production slightly. This agreement is individually rational as Firm 1 sells the same amount of products at a higher price, while Firm 2 avoids selling a loss-making item and enjoys a higher margin on its remaining sales. The cartel contract has a positive impact on total surplus as it prevents (part of) the losses from trade in competition and does not create a deadweight loss. In fact, in this case there exists a cartel that would lead to an increase of allocative efficiency.

Second, an individually rational welfare-enhancing weak cartel may exist when the price-cost margin is (weakly) positive for both firms at competitive production levels, i.e., $p^{*}-C_{2}^{\prime}\left(q_{2}^{*}\right) \geq 0$. Following Theorem 1 , such a cartel does exist whenever

$$
p^{*}-C_{2}^{\prime}\left(q_{2}^{*}\right)<\alpha\left(p^{*}-C_{1}^{\prime}\left(q_{1}^{*}\right)\right), \quad \text { with } \alpha \equiv \frac{p^{* \prime} q_{2}^{*}}{p^{* \prime} q_{2}^{*}-\left(p^{*}-C_{1}^{\prime}\left(q_{1}^{*}\right)\right)}
$$

Observe that (8) in combination with Assumption 1 implies that $p^{*}-C_{1}^{\prime}\left(q_{1}^{*}\right)>0$ and therefore $\alpha \in(0,1)$. For (8) to apply, we then must have that $p^{*}-C_{1}^{\prime}\left(q_{1}^{*}\right)>$ $p^{*}-C_{2}^{\prime}\left(q_{2}^{*}\right)$ or $C_{2}^{\prime}\left(q_{2}^{*}\right)>C_{1}^{\prime}\left(q_{1}^{*}\right)$, because $\alpha<1$.

Thus, given that the price-cost margin is positive for both firms, the existence of a welfare-enhancing weak cartel requires a difference in unit costs at competitive production levels. The following result shows that this difference must be sufficiently large, which depends on the price elasticity of demand $\varepsilon \equiv-\frac{\partial Q}{\partial p} \frac{p^{*}}{Q^{*}}$ and the market share of the less efficient firm $s_{2}=\frac{q_{2}^{*}}{Q^{*}}$.

Corollary 1 If $p^{*}-C_{2}^{\prime}\left(q_{2}^{*}\right) \geq 0$, then there exists an individually rational welfareenhancing weak cartel if and only if:

$$
p^{*}-C_{2}^{\prime}\left(q_{2}^{*}\right)<\frac{s_{2}}{\varepsilon\left(\frac{p^{*}-C_{1}^{\prime}\left(q_{1}^{*}\right)}{p^{*}}\right)}\left(C_{2}^{\prime}\left(q_{2}^{*}\right)-C_{1}^{\prime}\left(q_{1}^{*}\right)\right) .
$$

The intuition behind this result is as follows. For an increase of aggregate welfare, profits must be sufficiently higher under a cartel regime so as to more than offset the loss in consumer surplus. Given that total industry production is lower with a cartel, this implies that the less efficient firm has to reduce its output, while the more efficient firm has to increase its production (by a smaller amount). This has two effects. First, there is a total cost reduction resulting from a shift in production from the inefficient to the efficient firm. This positively affects both profits and welfare. Second, the output reduction (and price increase) caused by the cartel has a positive impact on profits, but a negative impact on welfare. For the cartel to be welfare-enhancing, we must have that the first effect dominates the second, which is the case when the difference in unit costs is sufficiently large. 
Notice that whether the difference in unit costs is sufficient in part depends on the price elasticity of demand. In particular, the required difference in productive efficiency is smaller the more inelastic is demand, all else equal. The reason for this is that the deadweight loss created by the cartel is positively related to the price elasticity of demand. Moreover, the elasticity of demand affects the maximum level of collusive prices and therefore the profit potential of collusion. Specifically, firms can raise prices more the more inelastic is market demand, all else unchanged. Thus, lower market demand elasticity not only implies more profit opportunities from collusion, but also makes it more likely that the cartel is welfare-enhancing. Note, however, that the impact of demand elasticity on the likelihood of collusion is ambiguous as it has a similar effect on both deviating profits as well as the effectiveness of the punishment strategy. ${ }^{19}$

As to the individual rationality requirement, observe that the efficient firm always finds it in its interest to take part in the cartel, because it will sell more products at a higher price. However, the less efficient firm wants to participate only if it is sufficiently compensated for its losses due to lower output. This is the case when it experiences a sufficient increase in the price-cost margin of its remaining production. If the less efficient firm has a large market share, then the higher price-cost margin caused by the cartel has a significant impact as remaining production is still substantial. Thus, the above situation is more likely to apply, the larger the market share of the less efficient firm, all else equal. Also, the increase in the price-cost margin depends negatively on the elasticity of demand. Therefore, ceteris paribus, it is easier to sufficiently compensate the less efficient firm when demand is relatively inelastic. Finally, the increase in price-cost margin is more likely to be sufficient when unit costs of the less efficient firm are relatively high in competition. The reason for this is that under a cartel regime it gives up part of its production for which profits are limited. As before, this makes it more likely that the higher margin on remaining production is sufficient to compensate for the loss in sales.

\subsection{Strong cartels}

Directing our attention to strong cartels, the issue is under what circumstances Condition 1 and Condition 2(ii) hold simultaneously. As the following Lemma indicates, it suffices to focus exclusively on Condition 1.

Lemma 2 If Condition 1 is satisfied, then Condition 2(ii) is satisfied.

Using the above result, the next theorem shows necessary and sufficient conditions for the existence of an individually rational welfare-enhancing strong cartel.

Theorem 2 There exists an individually rational welfare-enhancing strong cartel if and only if:

\footnotetext{
19 Schultz (2005), for example, investigates the relation between consumers' price information and tacit collusion. In general, the level of market transparency on the consumer side is positively correlated with deviating profits as a firm can attract more customers by cutting price. Yet, it also makes competition for customers more fierce and therefore allows for a stronger punishment in the event of defection. In other words, demand elasticity typically affects in the same way both sides of the incentive compatibility constraint. For a brief discussion of this issue, see Chapter 4 of Motta (2004).
} 
(i) $C_{1}^{\prime}\left(q_{1}^{*}\right)<C_{2}^{\prime}\left(q_{2}^{*}\right)$, or

(ii) $C_{1}^{\prime}\left(q_{1}^{*}\right)=C_{2}^{\prime}\left(q_{2}^{*}\right)>p^{*}$.

The first part of Theorem 2 reveals that an individually rational welfare-enhancing strong cartel exists whenever there is a difference in unit costs at competitive production levels. To see that this is sufficient, note that in light of Assumption 1 it is possible to shift some production from the less efficient firm to the more efficient firm. If firms would keep total output constant (a one-to-one shift), then total profits would increase. In this case, consumer welfare remains unaffected so that total surplus would increase as well. As production is a continuous variable, there exists an output level that is smaller than but sufficiently close to $Q^{*}$ such that both profits and welfare are higher compared to the competitive alternative.

It is noteworthy that an analogous result can be found in the literature on mergers. In general, if two or more firms combine productive assets and reallocate a significant part of production to the more efficient firm(s), then this may well lead to an increase of total surplus. If cost savings are substantial, then this might hold even absent synergies and with higher post-merger prices. For example, under the assumption that firms produce homogeneous goods and behave as Cournot competitors, Farrell and Shapiro (1990) provide sufficient conditions for a profitable merger to raise welfare. The above result is in a sense complementary as a profitable shift in output may generate more welfare under different behavioral assumptions, when products are differentiated and the number of firms remains unaltered. ${ }^{20}$

The second part of Theorem 2 shows that an individually rational welfare-enhancing strong cartel also exists when marginal production costs are equal and exceed the selling price at competitive production levels. This situation satisfies the condition of Theorem 1 above. As with weak cartels, when the unit costs of the last item(s) sold exceed price, then it is profitable to cut back production. Lowering production avoids (part of) the unprofitable sales and yields an increase of the price-cost margin on remaining sales. If the reduction in output is limited, then a hard core cartel increases instead of decreases allocative efficiency and is thereby contributing to social welfare.

\section{Discussion}

In a simple but fairly general setting, we have derived necessary and sufficient conditions for the existence of an individually rational welfare-enhancing hard core cartel. We considered both strong and weak hard core cartel contracts and found that (i) both strong and weak welfare-enhancing cartels exist when at least one firm makes a loss on part of its sales in competition, (ii) a welfare-enhancing strong cartel exists whenever there is a difference in unit costs at competitive production levels, and (iii) a welfare-enhancing weak cartel exists when the profit-margin on all sales is positive provided that the cost difference is sufficiently large. In thinking about these results, there are at least three issues that warrant discussion. First, to what extent are our

\footnotetext{
20 In Bos and Pot (2010) we provide several examples of how our findings apply to standard textbook models of price and quantity competition.
} 
results model specific? Second, if and to what extent can we expect the identified conditions to apply in practice? And third, what are potential implications of our findings for antitrust policy?

The first issue is to what extent our results are model specific. One may, for example, wonder whether our results will hold in a dynamic setting. In our analysis, we abstracted from issues related to cartel formation and cartel sustainability. Note, however, that the requirement that both firms benefit from the cartel implies that forming the cartel is individually rational. Moreover, in the context of an infinitely repeated game, such an agreement can be enforced by standard means (e.g., trigger strategies) provided that both firms are sufficiently patient. Therefore, one should expect our analysis to mark a lower bound on the size of the set of welfare-enhancing cartel contracts. A dynamic model would, for instance, allow for an analysis of the welfare impact of so-called structural crisis cartels. During an economic crisis such cartel agreements may allow for a smooth reconstruction of the industry and an orderly withdrawal of firms from the market. In the long run, crisis cartels may be superior in terms of social welfare as excess capacity during recessions may lead to destructive competition. ${ }^{21}$ More generally, taking a dynamic approach will, in all likelihood, enlarge the set of welfare-enhancing hard core cartel contracts, because there typically are more possibilities to save on total costs of production.

Moreover, our focus has been on what is arguably the "most evil" of all cartel contracts; those that exclusively lead to lower output and higher prices. In the above setting, whether or not such agreements yield an increase in total surplus solely depends on the condition as given in (4). This condition reveals that what is needed for a hard core cartel to be welfare-enhancing is a sufficient decrease in total production costs. We have derived results for given cost functions. Clearly, one could extent our setting by taking account of potential synergies or additional costs of production. For example, Doyle and Han (2009) analyze a model in which colluding firms form so-called buyer groups. This buyer group may effectively lower marginal production costs which, depending on the magnitude, may benefit both customers and society at large. Deltas et al. (2009) use a spatial setting to show that collusion may promote the welfare of both customers and society when savings on transportation costs under the cartel regime are substantial. These contributions suggest that allowing for 'a shift of the cost functions' is likely to enlarge the set of welfare-enhancing hard core cartels. In a similar vein, welfare-enhancing hard core cartels may exist when there are additional costs of production that are not incurred by firms. For example, in industries that exhibit severe negative externalities in production, a naked hard core cartel arrangement can be beneficial in terms of social welfare when the agreed upon cartel production is closer to the social optimum.

The second question concerns the degree of realism of the results derived above. We have used a framework that is quite similar to the static textbook model of collusion that is frequently applied to illustrate the harmful effects of hard core cartels. In this setting, we have demonstrated that one can identify situations in which hard

\footnotetext{
21 In the U.S., structural crisis cartels, like other hard core cartels, are subject to the per se rule under the Sherman Act. By contrast, in Europe these type of cartels are sometimes permitted. See, for instance, Commission Decision 4 July 1984 OJ L 207/17 (EC synthetic fibres industry).
} 
core cartels may lead to an increase of total surplus. Clearly, whether and how often such situations occur in practice is ultimately an empirical question and is likely to depend on the industry under consideration. However, it seems that the conditions under which a welfare-enhancing hard core cartel exists do not hold in rare cases only. For instance, firms having different unit costs at competitive production levels is likely to be the rule rather than the exception.

Yet, it should be emphasized that the mere fact that a welfare-enhancing hard core cartel exists does not imply that firms will actually form such an agreement. Even though Condition 2 guarantees that it might be individually rational to establish a welfare-enhancing cartel agreement, firms often have a whole set of sustainable collusive strategies available and it seems unlikely that every viable cartel contract will yield an increase of aggregate welfare. In the theory of collusion, it is common to assume that firms will choose the cartel contract(s) that maximize firms' profits. In the above framework, it appears difficult to draw general conclusions about whether and when the set of welfare-enhancing cartels contains the profit-maximizing cartel. However, to illustrate that this possibility is real, consider the following example.

Example Suppose that the market demand function is given by $Q(p)=1-10 p$ and that firms have identical cost functions $C\left(q_{i}\right)=\frac{1}{4} q_{i}^{2}$. Thus, unit costs are $\frac{1}{2} q_{i}$, for $i=1,2$. Total profits and consumer surplus are then respectively given by

$$
\pi=\pi_{1}+\pi_{2}=(1-10 p)\left(p-\frac{1}{8}(1-10 p)\right),
$$

and

$$
C S=\frac{1}{2}(1-10 p)\left(\frac{1}{10}-p\right) .
$$

Hence, total welfare equals,

$$
W=(1-10 p)\left(p-\frac{1}{8}(1-10 p)\right)+\frac{1}{2}(1-10 p)\left(\frac{1}{10}-p\right)
$$

Now suppose that $p=\frac{1}{18}$ (Notice that this is a Nash equilibrium price at which both firms make zero competitive profits). In this case, aggregate welfare is equal to $W=\frac{8}{810}$. A profit-maximizing cartel would charge a cartel price of $p^{c}=\frac{7}{90}$, which yields total cartel profits equal to $\pi^{c}=\frac{1}{90}$ and total welfare $W^{c}=\frac{11}{810}$. Consequently, a profit-maximizing cartel may lead to an increase of aggregate welfare.

The above illustrates that formulating policy implications on the basis of our findings is everything but trivial. As mentioned, if and how often the existence conditions for a welfare-enhancing hard core cartel hold is ultimately an empirical question and is likely to depend on the (type of) industry under consideration. An interesting and important research question is to explore what optimal antitrust enforcement looks like in a setting where the (unknown) pool of potential cartels contains both 'good cartels' and 'bad cartels'. An improvement of the antitrust system might be within 
reach if one would have a means to discriminate between efficient and inefficient cartel arrangements. Clearly, determining whether or not a potential cartel harms or contributes to social welfare is not an easy task. The answer might lie in modifying the current system in such a way that potential 'good cartels' have an incentive to reveal their type. When feasible, such a system would allow for the possibility to grant an exemption on the basis of the welfare effects of the potential cartel agreement. It is, however, a priori unclear whether and in what way relaxing the per se rule would indeed lead to higher welfare standards. We leave this issue for future research.

Acknowledgments We are indebted to Marco Haan, Joe Harrington, Ronald Peeters, Hans Peters, Dries Vermeulen, participants at the 2010 International Industrial Organization Conference in Vancouver, participants at the 2010 European Association for Research in Industrial Economics Conference in Istanbul and two anonymous referees for helpful comments and suggestions.

Open Access This article is distributed under the terms of the Creative Commons Attribution License which permits any use, distribution, and reproduction in any medium, provided the original author(s) and the source are credited.

\section{Appendix: Proofs}

Proof of Lemma 1 Suppose that, given a competitive situation $\left(p^{*}, q_{1}^{*}, q_{2}^{*}\right), \pi_{i}^{\prime}\left(q_{i}^{*}\right) \geq$ 0 for $i=1,2$. Suppose further that there exists a direction $\mathbf{u}=\left(u_{1}, u_{2}\right)$ for which Condition 1 and Condition 2(i) are satisfied. We will show that this yields a contradiction. We can distinguish two cases: $u_{1}>0$ and $u_{1} \leq 0$.

1. If $u_{1}>0$, then it must be the case that $u_{2}>0$, because otherwise Condition 2(i) is violated for firm 2. However, $u_{1}>0$ and $u_{2}>0$ is not allowed as $u_{1}+u_{2}<0$ by assumption.

2. If $u_{1} \leq 0$, then it must be the case that $u_{2}<0$, because otherwise Condition 2(i) is violated for firm 1 . This implies $u_{1}<0$, because otherwise Condition 2(i) is violated for firm 2. For Condition 1 to hold with $u_{1}<0$ and $u_{2}<0$, we then need that $p^{*}-C_{2}^{\prime}\left(q_{2}^{*}\right)<0$ as $C_{1}^{\prime}\left(q_{1}^{*}\right) \leq C_{2}^{\prime}\left(q_{2}^{*}\right)$ by Assumption 1 . However, if $p^{*}-C_{2}^{\prime}\left(q_{2}^{*}\right)<0$, then $p^{*}-C_{2}^{\prime}\left(q_{2}^{*}\right)+p^{* \prime} q_{2}^{*}<0$, because $p^{* \prime} q_{2}^{*}<0$. Thus, $\pi_{2}^{\prime}\left(q_{2}^{*}\right)<0$, which yields a contradiction.

Proof of Theorem 1 By Lemma 1, we know that a necessary condition for the existence of an individually rational welfare-enhancing weak cartel is that $\pi_{i}^{\prime}\left(q_{i}^{*}\right)<0$ for at least one firm $i$. What remains is to derive sufficient conditions for the existence of such a cartel. We can distinguish two cases: (1) $p^{*}-C_{i}^{\prime}\left(q_{i}^{*}\right)<0$, for at least one firm $i$, and (2) $p^{*}-C_{i}^{\prime}\left(q_{i}^{*}\right) \geq 0$, for $i=1,2$. We show for both cases if and when a direction $\mathbf{u}=\left(u_{1}, u_{2}\right)$ with $u_{1}+u_{2}<0$ exists for which Condition 1 and Condition 2(i) are satisfied.

1. Suppose that $p^{*}-C_{i}^{\prime}\left(q_{i}^{*}\right)<0$, for at least one firm $i$. By Assumption 1 , we know that $C_{1}^{\prime}\left(q_{1}^{*}\right) \leq C_{2}^{\prime}\left(q_{2}^{*}\right)$, which implies $p^{*}-C_{2}^{\prime}\left(q_{2}^{*}\right)<0$. In this case, Conditions 1 and 2(i) can be satisfied simultaneously with, for instance, $u_{1}=0$ and $u_{2}<0$.

2. Suppose that $p^{*}-C_{i}^{\prime}\left(q_{i}^{*}\right) \geq 0$, for $i=1,2$. By Assumption 1 , it follows that $p^{*}-C_{1}^{\prime}\left(q_{1}^{*}\right) \geq p^{*}-C_{2}^{\prime}\left(q_{2}^{*}\right) \geq 0$. In order for Condition 1 to hold, we thus need 
that $u_{1}>0$ and $u_{2}<0$ with $\left|u_{2}\right|>u_{1}$. More specifically, for the cartel to be welfare-enhancing, it is required that

$$
u_{2}>-u_{1} \frac{p^{*}-C_{1}^{\prime}\left(q_{1}^{*}\right)}{p^{*}-C_{2}^{\prime}\left(q_{2}^{*}\right)},
$$

with $u_{1}>0$ and $u_{2}<0$. Following Condition 2(i), firm 1 find it in its interest to take part in the cartel when

$$
u_{1} \cdot\left(p^{*}-C_{1}^{\prime}\left(q_{1}^{*}\right)\right)+\left(u_{1}+u_{2}\right) \cdot p^{* \prime} q_{1}^{*}>0 \text { with } u_{1}+u_{2}<0 .
$$

Hence, Condition 2(i) is satisfied for firm 1, because $p^{* \prime} q_{1}^{*}<0, u_{1}>0$ and $p^{*}-C_{1}^{\prime}\left(q_{1}^{*}\right)>0$. Notice that, for Condition 2(i) to hold for firm 2, it is required that $\pi_{2}^{\prime}\left(q_{2}^{*}\right)<0$ and

$$
u_{2}<-u_{1} \frac{p^{* \prime} q_{2}^{*}}{p^{*}-C_{2}^{\prime}\left(q_{2}^{*}\right)+p^{* \prime} q_{2}^{*}} .
$$

Combining (9) with (10) then defines an interval of values for $u_{2}$ for which the cartel is individually rational and welfare-enhancing:

$$
-u_{1} \frac{p^{*}-C_{1}^{\prime}\left(q_{1}^{*}\right)}{p^{*}-C_{2}^{\prime}\left(q_{2}^{*}\right)}<u_{2}<-u_{1} \frac{p^{* \prime} q_{2}^{*}}{p^{*}-C_{2}^{\prime}\left(q_{2}^{*}\right)+p^{* \prime} q_{2}^{*}} .
$$

Thus, there exists a value $u_{2}$ for which (9) and (10) hold simultaneously when

$$
\frac{p^{*}-C_{1}^{\prime}\left(q_{1}^{*}\right)}{p^{*}-C_{2}^{\prime}\left(q_{2}^{*}\right)}>\frac{p^{* \prime} q_{2}^{*}}{p^{*}-C_{2}^{\prime}\left(q_{2}^{*}\right)+p^{* \prime} q_{2}^{*}} .
$$

Rearranging yields,

$$
p^{*}-C_{2}^{\prime}\left(q_{2}^{*}\right)<\frac{p^{* \prime} q_{2}^{*}\left(p^{*}-C_{1}^{\prime}\left(q_{1}^{*}\right)\right)}{p^{* \prime} q_{2}^{*}-\left(p^{*}-C_{1}^{\prime}\left(q_{1}^{*}\right)\right)} .
$$

Notice that, in light of case 1 above, (11) is effective only when the right-hand side of (11) is positive. If this is the case, then $\pi_{2}^{\prime}\left(q_{2}^{*}\right)<0$. To see this, add $p^{* \prime} q_{2}^{*}$ to both sides of (11), which yields

$$
p^{*}-C_{2}^{\prime}\left(q_{2}^{*}\right)+p^{* \prime} q_{2}^{*}<\frac{p^{* \prime} q_{2}^{*}\left(p^{*}-C_{1}^{\prime}\left(q_{1}^{*}\right)\right)}{p^{* \prime} q_{2}^{*}-\left(p^{*}-C_{1}^{\prime}\left(q_{1}^{*}\right)\right)}+p^{* \prime} q_{2}^{*},
$$

which is equivalent to

$$
\pi_{2}^{\prime}\left(q_{2}^{*}\right)<p^{* \prime} q_{2}^{*}\left(\frac{p^{* \prime} q_{2}^{*}}{p^{* \prime} q_{2}^{*}-\left(p^{*}-C_{1}^{\prime}\left(q_{1}^{*}\right)\right)}\right) .
$$


The right-hand side of (12) is negative. Hence, $\pi_{2}^{\prime}\left(q_{2}^{*}\right)<0$ and the requirement of

Lemma 1 is met.

Proof of Corollary 1 Suppose that $p^{*}-C_{2}^{\prime}\left(q_{2}^{*}\right) \geq 0$. Following Theorem 1, an individually rational welfare-enhancing weak cartel exists if and only if

$$
p^{*}-C_{2}^{\prime}\left(q_{2}^{*}\right)<\frac{p^{* \prime} q_{2}^{*}\left(p^{*}-C_{1}^{\prime}\left(q_{1}^{*}\right)\right)}{p^{* \prime} q_{2}^{*}-\left(p^{*}-C_{1}^{\prime}\left(q_{1}^{*}\right)\right)} .
$$

Multiplying the numerator and denominator at the right-hand side of (13) with $-\frac{Q^{*}}{Q^{*} p^{*}}$ yields

$$
p^{*}-C_{2}^{\prime}\left(q_{2}^{*}\right)<\frac{s_{2}}{s_{2}+\varepsilon\left(\frac{p^{*}-C_{1}^{\prime}\left(q_{1}^{*}\right)}{p^{*}}\right)}\left(p^{*}-C_{1}^{\prime}\left(q_{1}^{*}\right)\right)
$$

where $\varepsilon \equiv-\frac{\partial Q}{\partial p} \frac{p^{*}}{Q^{*}}$ and $s_{2}=\frac{q_{2}^{*}}{Q^{*}}$. Rearranging this term yields

$$
s_{2}\left(p^{*}-C_{2}^{\prime}\left(q_{2}^{*}\right)\right)+\varepsilon\left(\frac{p^{*}-C_{1}^{\prime}\left(q_{1}^{*}\right)}{p^{*}}\right)\left(p^{*}-C_{2}^{\prime}\left(q_{2}^{*}\right)\right)<s_{2}\left(p^{*}-C_{1}^{\prime}\left(q_{1}^{*}\right)\right),
$$

which is equivalent to

$$
p^{*}-C_{2}^{\prime}\left(q_{2}^{*}\right)<\frac{s_{2}}{\varepsilon\left(\frac{p^{*}-C_{1}^{\prime}\left(q_{1}^{*}\right)}{p^{*}}\right)}\left(C_{2}^{\prime}\left(q_{2}^{*}\right)-C_{1}^{\prime}\left(q_{1}^{*}\right)\right) .
$$

Proof of Lemma 2 Consider Condition 2(ii):

$u_{1} \cdot\left(p^{*}-C_{1}^{\prime}\left(q_{1}^{*}\right)\right)+u_{2} \cdot\left(p^{*}-C_{2}^{\prime}\left(q_{2}^{*}\right)\right)+\left(u_{1}+u_{2}\right) \cdot p^{* \prime} Q^{*}>0 \quad$ with $u_{1}+u_{2}<0$.

As $u_{1}+u_{2}<0$, we know that $\left(u_{1}+u_{2}\right) \cdot p^{* \prime} Q^{*}>0$ at all $Q^{*}>0$. Hence, Condition 2(ii) holds whenever

$$
u_{1} \cdot\left(p^{*}-C_{1}^{\prime}\left(q_{1}^{*}\right)\right)+u_{2} \cdot\left(p^{*}-C_{2}^{\prime}\left(q_{2}^{*}\right)\right)>0,
$$

which is Condition 1. Therefore, whenever Condition 1 is satisfied, Condition 2(ii) is satisfied as well.

Proof of Theorem 2 Notice that by Lemma 2 it is sufficient to focus exclusively on Condition 1.

- Part (i): Suppose $C_{1}^{\prime}\left(q_{1}^{*}\right)<C_{2}^{\prime}\left(q_{2}^{*}\right)$ and therefore $p^{*}-C_{1}^{\prime}\left(q_{1}^{*}\right)>p^{*}-C_{2}^{\prime}\left(q_{2}^{*}\right)$. Now consider the direction $\mathbf{u}=\left(u_{1}, u_{2}\right)$ with $u_{1}>0$ and $u_{2}<-u_{1}$ (so that $u_{1}+u_{2}<0$ ). We can distinguish three cases: (1) price is equal to marginal cost of firm 1, (2) price is higher than marginal cost for firm 1 and (3) price is lower than marginal cost for firm 1 . We show for each case that a direction $\mathbf{u}=\left(u_{1}, u_{2}\right)$ with $u_{1}+u_{2}<0$ exists such that Condition 1 can be satisfied. 
1. $p^{*}-C_{1}^{\prime}\left(q_{1}^{*}\right)=0$ or $p^{*}-C_{2}^{\prime}\left(q_{2}^{*}\right)=0$. It follows immediately that Condition 1 is satisfied.

2. $p^{*}-C_{1}^{\prime}\left(q_{1}^{*}\right)>0$. In this case, Condition 1 holds whenever there exists a direction $\mathbf{u}$ such that

$$
\frac{u_{1}}{-u_{2}}>\frac{p^{*}-C_{2}^{\prime}\left(q_{2}^{*}\right)}{p^{*}-C_{1}^{\prime}\left(q_{1}^{*}\right)} .
$$

As $\frac{u_{1}}{-u_{2}} \in(0,1),(14)$ always holds for $p^{*}-C_{2}^{\prime}\left(q_{2}^{*}\right) \leq 0$. If $p^{*}-C_{2}^{\prime}\left(q_{2}^{*}\right)>0$, then

$$
0<\frac{p^{*}-C_{2}^{\prime}\left(q_{2}^{*}\right)}{p^{*}-C_{1}^{\prime}\left(q_{1}^{*}\right)}<1 .
$$

Notice that, as $\frac{u_{1}}{-u_{2}} \in(0,1)$, there always exist values for $u_{1}$ and $u_{2}$ such that

$$
1>\frac{u_{1}}{-u_{2}}>\frac{p^{*}-C_{2}^{\prime}\left(q_{2}^{*}\right)}{p^{*}-C_{1}^{\prime}\left(q_{1}^{*}\right)}>0 .
$$

3. $p^{*}-C_{1}^{\prime}\left(q_{1}^{*}\right)<0$. In this case, Condition 1 holds whenever there exists a direction u such that

$$
\frac{u_{1}}{-u_{2}}<\frac{p^{*}-C_{2}^{\prime}\left(q_{2}^{*}\right)}{p^{*}-C_{1}^{\prime}\left(q_{1}^{*}\right)} .
$$

As $\frac{p^{*}-C_{2}^{\prime}\left(q_{2}^{*}\right)}{p^{*}-C_{1}^{\prime}\left(q_{1}^{*}\right)}>1$ and $\frac{u_{1}}{-u_{2}} \in(0,1),(15)$ always holds.

- Part (ii): Suppose $C_{1}^{\prime}\left(q_{1}^{*}\right)=C_{2}^{\prime}\left(q_{2}^{*}\right)=C$. In this case, Condition 1 simplifies to $\left(u_{1}+u_{2}\right) \cdot\left(p^{*}-C\right)>0$. As $u_{1}+u_{2}<0$, Condition 1 is only satisfied when $p^{*}<C$.

\section{References}

Bittlingmayer G (1995) Output and Stock prices when antitrust is suspended: the effects of the NIRA. In: McChesney FS, Shughart II WF (eds) The causes and consequences of antitrust: the public choice perspective. The University of Chicago Press, Chicago, pp 287-318

Bittlingmayer G (1982) Decreasing average cost and competition: a new look at the Addyston pipe case. J Law Econ 25:201-229

Bork RH (1993) The antitrust paradox: a policy at war with itself. The Free Press, New York

Bos I, Pot E (2010) Welfare-enhancing hard core cartels. METEOR Research Memorandum, 10/004, Maastricht University

Deltas G, Salvo A, Vasconcelos H (2009) Welfare-enhancing collusion and trade. Working Paper Dewey D (1979) Information, entry and welfare: the case for collusion. Am Econ Rev 69(4):587-594 Dick AR (1996) When are cartels stable contracts? J Law Econ 39:241-283

Doyle C, Han MA (2009) Efficient cartelization through buyer groups. ACLE Working Paper, No. 2009-03 Farrell J, Shapiro C (1990) Horizontal mergers: an equilibrium analysis. Am Econ Rev 80(1):107-126 
Fershtman C, Pakes A (2000) A dynamic oligopoly with collusion and price wars. RAND J Econ 31(2):207236

Genesove D, Mullin WP (2001) Rules, communication, and collusion: narrative evidence from the Sugar Institute Case. Am Econ Rev 91(3):379-398

Harrington JE Jr (2006) How do cartels operate? Found Trends Microecon 2(1):1-105

Hüschelrath K, Weigand J (2010) Fighting hard core cartels. ZEW Discussion Paper, No. 10-084

Kinghorn JR (1996) Kartells and Cartel theory: evidence from early twentieth century German Coal, Iron and Steel Industries. Essays Econ Business Hist 14:339-363

Matsui A (1989) Consumer-benefited cartels under strategic capital investment competition. Int J Ind Organ 7:451-470

Montero J-P, Guzmán JI (2010) Output-expanding collusion in the presence of a competitive fringe. J Ind Econ 58(1):106-126

Motta M (2004) Competition policy: theory and practice. Cambridge University Press, Cambridge

OECD (2000) Hard core cartels. OECD reports

OECD report (1998) Recommendation of the council concerning effective action against hard core cartels. OECD Recommendations \& Best Practices

Pesendorfer M (2000) A study of collusion in first-price auctions. Rev Econ Stud 67(3):381-411

Röller L-H, Steen F (2006) On the workings of a cartel: evidence from the Norwegian cement industry. Am Econ Rev 96(1):321-338

Rotemberg JJ (1998) Government-enforced cartels, output and welfare. Harvard Business School Working Paper, No. 98-116

Schultz C (2005) Transparancy on the consumer side and tacit collusion. Eur Econ Rev 49:279-297

Sjostrom W (1989) Collusion in ocean shipping: a test of monopoly and empty core models. J Political Econ 97(5):1160-1179

Spagnolo G (2006) Criminalization of cartels and their internal organization. In: Cseres KJ, Schinkel MP, Vogelaar FOW (eds) Criminalization of competition law enforcement. Edward Elgar, Cheltenham, pp 133-149

Sproul MF (1993) Antitrust and prices. J Political Econ 101(4):741-754

Taylor JE (2002) The output effects of government sponsored cartels during the new deal. J Ind Econ 50(1): $1-10$

Telser LG (1996) Competition and the core. J Political Econ 104(1):85-107

Troesken W (1989) A note on the efficacy of the German steel and coal syndicates. Explor Econ Hist 18:595-600

Williamson OE (1968) Economies as an antitrust defense: the welfare tradeoffs. Am Econ Rev 58(1):18-36 